J. Lake Sci.(湖泊科学), 2008, 20(3): 327-333

http://www.jlakes.org. E-mail: jlakes@niglas.ac.cn

(C)2008 by Journal of Lake Sciences

\title{
不同水生植物对湿地无机氮素去除效果的模拟*
}

\author{
万晓红 ${ }^{1}$, 李旭东 ${ }^{1,2}$, 王雨春 ${ }^{1}$, 陆 瑾 $^{1}$, 赵茵茵 ${ }^{3}$, 刘玲花 ${ }^{1}$, 周怀东 ${ }^{* * *}$ \\ (1: 中国水利水电科学研究院, 北京 100038) \\ (2: 内蒙古乌海市环境监测中心, 乌海 016000) \\ (3: 水利部海河流域水利委员会, 天津 300170)
}

摘 要: 分别以芦苇、花叶水葱和苦草构建成小规模人工湿地模拟系统, 开展不同类型水生植物湿地中无机氮(硝态氮和铵态 氮)去除效果的试验. 试验结果表明: 在分别以芦苇、花叶水苟和苦草构成的模拟湿地单元中, 虽然氧化还原等环境条件呈现 较大差异, 但不同类型水生植物湿地单元的铵态氮和硝态氮的去除率并没有显著差别, 这与以往关于不同类型水生植物对氮 素去除贡献的认识有所不同; 水生植物对模拟湿地体系中氮素的去除具有重要作用, 在相对较低的氮负荷 $\left(\mathrm{NH}_{4}{ }^{+} \mathrm{-}-\mathrm{N}\right.$ 约为 $2.85 \mathrm{mg} / \mathrm{L}, \mathrm{NO}_{3}{ }^{-}-\mathrm{N}$ 约为 $1.07 \mathrm{mg} / \mathrm{L}$, 相当于一般城市污染河流)条件下, 有水生植物湿地单元中铵态氮和硝态氮的 $10 \mathrm{~d}$ 去除率分 别在 $39.32 \%$ 和 $21.91 \%$ 以上，而无水生植物的空白湿地单元对铵态氮和硝态氮的 $10 \mathrm{~d}$ 去除率分别只有 $34.68 \%$ 和 $13.86 \%$; 在 提高模拟湿地体系水体氮 $\left(\mathrm{NH}_{4}{ }^{+}-\mathrm{N}\right.$ 约为 $5.50 \mathrm{mg} / \mathrm{L}, \mathrm{NO}_{3}{ }^{-}-\mathrm{N}$ 约为 $3.37 \mathrm{mg} / \mathrm{L}$, 是一般城市污染程度的 2 倍)负荷条件下, 有水生植 物湿地单元中铵态氮和硝态氮的 $10 \mathrm{~d}$ 去除率分别大于或等于 $66.87 \%$ 和 $78.92 \%$ 以上, 而无水生植物的空白湿地单元对铵态氮 和硝态氮的 $10 \mathrm{~d}$ 去除率仅为 $40.62 \%$ 和 $31.77 \%$, 为人工湿地对原污水或初沉池出水的处理提供了有力依据. 试验结果还表明, 水生植物能有效促进湿地的氮素转化过程，显著缩短无机氮素在湿地中的寄宿时间.

关键词: 湿地; 水生植物; 铵态氮; 硝态氮; 氮去除

\section{Simulation of removal ammonia and nitrate from wetlands constructed by different hydrophytes}

WAN Xiaohong ${ }^{1}$, LI Xudong ${ }^{1,2}$, WANG Yuchun ${ }^{1}$, LU Jin $^{1}$, ZHAO Yinyin ${ }^{3}$, LIU Linghua ${ }^{1} \&$ ZHOU Huaidong ${ }^{1}$ (1: China Institute of Water Resources and Hydropower Research, Beijing 100038, P.R.China)

(2: Wuhai Environment Monitor Center, Wuhai 016000, Inner Mongolia Province of China, P.R.China)

(3: Haihe River Commission Ministry of Water Resources, Tianjin 300170, P.R.China)

Abstract: The hydrophyte has an important effect on removing nitrogen in the wetland system. This paper studied the nitrogen removal rate of the simulated wetland systems with Phragmites communis, Scirpus tabernaemontani cv.Zebrinus. and Vallisneria spiralis $L$. respectively. The hydrophytes had changed the redox condition markedly, however no significant discrepancies were found on the nitrogen removal rate. For the low nitrogen load $\left(2.85 \mathrm{mg} / \mathrm{L}\right.$ for $\mathrm{NH}_{4}{ }^{+}-\mathrm{N}$ and $1.07 \mathrm{mg} / \mathrm{L}$ for $\left.\mathrm{NO}_{3}{ }^{-} \mathrm{N}\right)$, the ten-day removal rate of Ammonium and Nitrate of the wetland systems with and without hydrophytes were $39.32 \%$ and $21.91 \%, 34.68 \%$ and $13.86 \%$ respectively. In contrast, for the high nitrogen load $\left(5.50 \mathrm{mg} / \mathrm{L}\right.$ for $\mathrm{NH}_{4}{ }^{+}-\mathrm{N}$, and $3.37 \mathrm{mg} / \mathrm{L}$ for $\left.\mathrm{NO}_{3}{ }^{-} \mathrm{N}\right)$, the ten-day removal rate of Ammonium and Nitrate of the wetland systems with and without hydrophytes were $66.87 \%$ and $78.92 \%, 40.62 \%$ and $31.77 \%$ respectively. The hydrophyte could promote the process of nitrous transfer and shorten the time of the nitrous stay in the wetland. Keywords: Wetland; hydrophytes; ammonium; nitrate; the removing of nitrogen

我国地表水环境的污染形势不容乐观，根据国家有关部门 2005 年的统计资料，七大水系的 411 个地表

* 国家自然科学基金项目(50579076)和国家 973 项目(2006CB403403)联合资助. 2007-04-13 收稿; 2007-08-29 收修改稿. 万晓红, 女, 1978 年生, 博士研究生; E-mail: wanxh@iwhr.com.

** 通讯作者; E-mail: HDZhou@iwhr.com. 

水监测断面中， I - III类、 $\mathrm{IV}-\mathrm{V}$ 类和劣 $\mathrm{V}$ 类水质的断面比例分别为 $41 \% 、 32 \%$ 和 $27 \%$, 其中海河水系属 重度污染，65 个地表水国控监测断面中，I-III类、IV-V 类和劣 V 类水质的断面比例分别为 $22 \% 、 24 \%$ 和 $54 \%$. 我国地表水环境普遍表现出以高氮负荷为主要特征的污染问题 ${ }^{[1]}$, 而氨氮和 COD 被列为实现我 国水污染治理国家目标的首要控制污染物.

湿地是水陆交错的特殊生态系统, 具有重要的水质净化功能. 自 20 世纪中叶, 人们就已开始使用湿 地处理生活污水 ${ }^{[2-3]}$. 由于湿地中淹水和非淹水条件的交替变化, 湿地可能发生强烈的硝化、反硝化等氮 素转化过程，湿地技术因此被认为是降低环境氮负荷的有效手段，而被广泛应用于面源污染控制、污染 受损水体修复、城市水系净化等环境治理工作中. 过去数十年中, 各国科学家开展了大量研究, 对湿地系 统中淋滤溶出、硝化和反硝化、氨挥发等氮素迁移转化的生物地球化学有了一定的认识 ${ }^{[4]}$.

湿地系统中水生植物对氮素的吸收、代谢及同化作用被认为是控制环境氮负荷的主要作用机制之一 ${ }^{[5]}$. 水生植物除了通过直接吸收机制同化固定环境中的无机氮素外, 它的生长过程对周围物理、化学和微生 物环境条件的改变, 也在很大程度上改变着氮素迁移、转化的归趋. 现有的研究认为, 挺水植物(芦苇等) 由于光合作用器官在水面之上, 因此, 以挺水植物为主的湿地水体环境通常相对戻氧, 有利于反硝化作 用进行; 相反, 沉水植物(苦草等)的光合作用主要在水下完成, 沉水植物的生理活动可能使水体溶解氧饱 和甚至过饱和，强烈的好氧环境有利于铵态氮氧化的硝化过程进行.

然而, 不同植物类型湿地中氮素转化的作用方式和强度可能有较大差别 ${ }^{[6]}$, 这也是环境生态工程中 湿地技术构建和运用的理论基础. 以往工作中, 水生植物对水体氮素迁移转化的影响一直是研究的重点, 但更多的是评价整个湿地系统的氮, 而对不同类型水生植物的贡献, 尤其对短时间尺度无机氮素转化的 研究相对较少 ${ }^{[7-9]}$. 为更好地揭示不同类型水生植物湿地环境中氮素的转化或去除效率, 本次工作在条件 可以人工控制的小规模湿地模拟系统中, 分别选择我国北方典型水生植物芦苇、花叶水葱和苦草构建湿 地系统, 研究不同污染负荷 (一般北方河流氮含量和两倍含量)条件下, 不同湿地环境中无机氮素的转化 或去除效率, 为不同水生植物在湿地生态工程中的运用提供有效数据和有益参考.

\section{1 材料与方法}

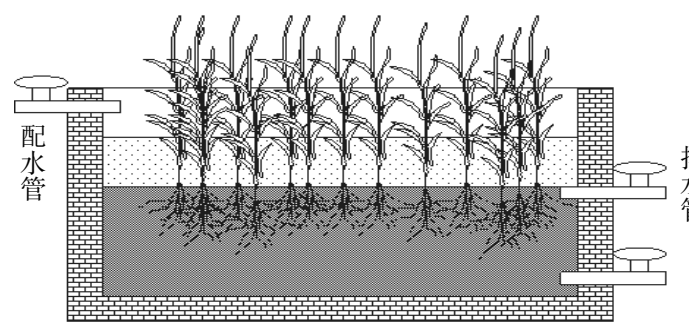

图 1 人工湿地模拟系统

Fig.1 The simulate wetland system

\section{1 试验系统的构建}

试验场地设在北京玉洲潭公园南侧昆玉河旁边 水生生态修复试验区内, 模拟湿地系统由湿地单元 (图 1)、配水(池)系统和进水系统组成. 一共有 10 个 水并联方式排列的 $4 \mathrm{~m} \times 2 \mathrm{~m} \times 1 \mathrm{~m}$ 的钢筋混凝土水池构 成的湿地单元, 水池底部 $30-40 \mathrm{~cm}$ 处为 $1-4 \mathrm{~mm}$ 过 節细砂, 上铺 $15-20 \mathrm{~cm}$ 厚壤土, 水池一侧的配水池 与各池由配水管相连, 且每个池子底部装有排水管, 可将池中水排出.

为了解不同水生植物对湿地中氮素的去除效果, 在模拟湿地单元中分别种植了芦苇(Phragmites australis)、花叶水苟(Scirpus tabernaemontani var. Zebrinus) 和苦草(Vallisneria natans)构建试验体系, 同时 设置无水生植物的模拟湿地单元作为空白对照. 用于研究的湿地, 已经过 3 年的保育熟化, 单元土壤介 质等基本条件稳定, 土壤有机质为 $4.1-5.9 \mathrm{~g} / \mathrm{kg}$, 全氮为 $0.5-0.6 \mathrm{~g} / \mathrm{kg}$, 全磷为 $0.44-0.51 \mathrm{~g} / \mathrm{kg}$.

试验用水通过抽取北京昆玉河玉沸潭段河水至配水池中，根据要求调节氮负荷后配送到各试验单元， 试验体系水深控制在 $30 \pm 2 \mathrm{~cm}$ 范围. 由于为静态试验, 因此, 每次试验前将湿地单元中存水放干, 重新加 人在配水池中固定浓度的试验用水, 进水后 $1 \mathrm{~h}$ 采样作为各池中的初始浓度. 每次测样后根据各池中水位 及氮素浓度分别配水补足蒸发和蒸腾掉的水分.

\section{2 采样与分析}

本次试验选择了植物生长活动旺盛的夏季进行, 分别按低负荷(水体起始无机氮浓度分别为 $\mathrm{NH}_{4}{ }^{+}-\mathrm{N}$ 约为 
$2.85 \mathrm{mg} / \mathrm{L}, \mathrm{NO}_{3}{ }^{-}-\mathrm{N}$ 约为 $1.07 \mathrm{mg} / \mathrm{L}$ ) 和高负荷 (水体起始无机氮浓度分别为 $\mathrm{NH}_{4}{ }^{+}-\mathrm{N}$ 约为 $5.50 \mathrm{mg} / \mathrm{L}, \mathrm{NO}_{3}{ }^{-}-\mathrm{N}$ 约为 $3.37 \mathrm{mg} / \mathrm{L}$ ) 条件进行试验，低负荷无机氮素的浓度水平相当于北京城市污染较重河流(如温榆河), 高负荷 无机氮浓度设置约为低负荷的 2 倍，大致相当于生活污水集中排放口的污染水平; 低负荷试验单元试验 时间为 $30 \mathrm{~d}$ ，高负荷试验单元试验时间为 $10 \mathrm{~d}$.

各试验单元按同样的时间间隔采集水样, 水样采集后立刻进行分析, $\mathrm{NH}_{4}{ }^{+}-\mathrm{N} 、 \mathrm{NO}_{3}{ }^{-}-\mathrm{N}$ 的分析方法分 别采用纳氏试剂光度法和酚二磺酸光度法完成 ${ }^{[10]}$, 分析仪器采用上海产 721 紫外分光光度仪; 水体中的 溶解氧浓度等指标通过便携式溶氧仪测定获得. 同时采集平行样，试验数据采用 Microsoft Excel 和 SPSS12.0 统计软件进行分析，根据下式计算水体中氮素的去除率 $(\%)$ :

$$
\text { 氮素去除率 }=\left(C_{0} \times V_{0}-C_{i} \times V_{i}\right) /\left(C_{0} \times V_{0}\right) \times 100
$$

式中: $C_{0}$ 为水体 $\mathrm{NH}_{4}{ }^{+}-\mathrm{N}$ 或 $\mathrm{NO}_{3}{ }^{-}-\mathrm{N}$ 初始浓度; $V_{0}$ 为初始水体积; $C_{i}$ 为第 $i$ 天的水体 $\mathrm{NH}_{4}{ }^{+}-\mathrm{N}^{-⿹}$ 或 $\mathrm{NO}_{3}{ }^{-}-\mathrm{N}$ 的 浓度; $V_{i}$ 为第 $i$ 天的水体积.

\section{2 结果分析与讨论}

\section{1 不同水生植物湿地单元水环境条件的变化特征}

湿地水生植物对湿地氮素生物地球化学循环过程的影响, 除通过直接的同化吸收外, 更重要的是通过 湿地环境条件改变来加强氮转化过程的 ${ }^{[11]}$.

在每次试验开始前, 由于补水的曝气过 程使各试验单元上覆水中溶解氧浓度接近溶 解饱和值(图 2). 随着试验进程的推进, 芦苇 和花叶水憼湿地单元中的溶解氧迅速降低, 试验结束时水体溶解氧的浓度分别为 $1.17 \mathrm{mg} / \mathrm{L}$ 和 $1.84 \mathrm{mg} / \mathrm{L}$; 而苦草湿地单元上覆 水体的溶解氧水平则表现出相反的变化趋势, 整个试验过程中溶解氧呈上升趋势, 溶解氧 浓度高达 $8.85 \mathrm{mg} / \mathrm{L}$; 无植物的空白对照湿地 单元上覆水体中溶解氧的含量略微降低. 试 验表明，苦草等沉水植物在水中的光合作用 放出氧气，使体系呈现好氧状态; 芦苇、花 叶水葱等挺水植物, 光合作用器官在水面以 上，只能通过植物组织进行氧气传输，而水 中污染物的降解耗氧量远大于植物输人的氧

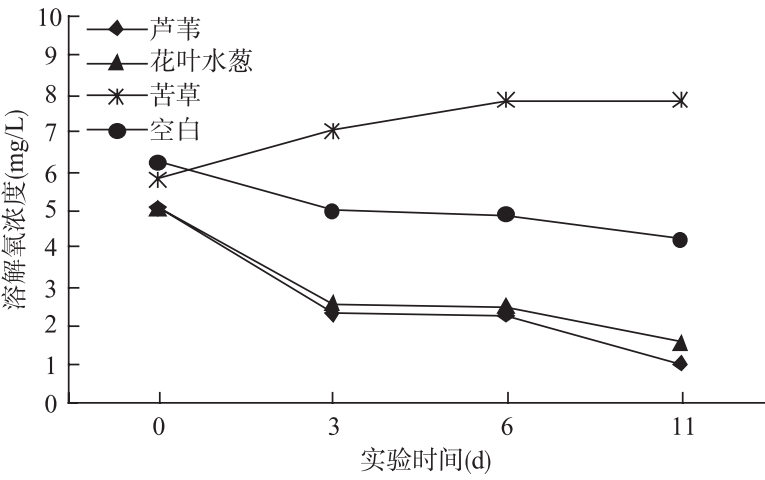

图 2 试验进程中不同水生植物湿地单元上覆 水体中溶解氧的变化

Fig.2 The concentration of dissolved oxygen in the wetland units with the different hydrophytes during the simulation 量，所以表现为溶氧的下降. 由此可以看出，与没有水生植物的空白湿地对比，芦苇和花叶水葱为主的 挺水植物会使湿地体系的水环境演化为相对厌氧的状态，而苦草为主的沉水植物可以使湿地体系水环境 向相对氧化状态演变.

\section{2 不同水生植物湿地单元对铵态氮 $\left(\mathrm{NH}_{4}{ }^{+}-\mathrm{N}\right)$ 的去除效果}

各试验体系水体铵态氮的变化趋势(图 3), 图中横坐标为试验时间, 纵坐标为水体铵态氮的去除率. 湿地单元中铵态氮的去除率随时间大致按对数增长变化. 在低负荷条件 $\left(\mathrm{NH}_{4}{ }^{+}-\mathrm{N}\right.$ 起始浓度 $\left.2.85 \mathrm{mg} / \mathrm{L}\right)$ 下， 不同水生植物湿地单元对铵态氮的去除效果均好于无植物空白对照湿地单元，10d 的去除率芦苇湿地为 $39.32 \%$, 花叶水葱湿地为 $44.87 \%$, 苦草湿地为 $46.10 \%$, 而空白湿地仅为 $34.68 \%$, 表明水生植物对水中 铵态氮的去除具有明显的作用. 根据湿地单元中铵态氮的去除率随时间变化的规律，预计在高氮负荷条 件下 $\left(\mathrm{NH}_{4}{ }^{+}-\mathrm{N}\right.$ 起始浓度 $\left.5.50 \mathrm{mg} / \mathrm{L}\right)$ 所有水生植物湿地单元中铵态氮都将有更高的去除率.

与空白湿地相比，高氮负荷条件下挺水植物芦苇、花叶水葱湿地单元的铵态氮去除效果明显好于沉 水植物苦草. 此现象发生的原因可能与挺水植物和沉水植物的形态特征有密切关系. 芦苇和花叶水葱的 根系均比苦草发达, 从而较大程度上改变了基质的结构, 为不同种类的微生物提供更多的生存条件. 有 
研究报道, 污水 $\mathrm{NH}_{4}{ }^{+}-\mathrm{N}$ 的去除率与根区的硝化细菌和反硝化细菌数量的相关性极显著 ${ }^{[12]}$. 通常认为, 在 高铵环境中沉水植物优先利用水中的铵态氮, 而很少吸收水中的硝态氮和底泥中的无机氮 ${ }^{[13-14]}$, 并且氧 化条件有利于铵态氮通过硝化作用转化为硝态氮, 而本试验结果与此不一致, 说明湿地氮转化过程具有 复杂性, 氧化还原条件不是铵态氮转化迁移的主要控制因素 ${ }^{[15-16]}$, 其原因有待进一步研究.

\section{3 不同水生植物湿地单元对硝态氮 $\left(\mathrm{NO}_{3}{ }^{-}-\mathrm{N}\right)$ 的去除效果}

各试验单元中硝态氮的浓度变化趋势 (以硝态氮减少的去除率表示), 横坐标为试验时间, 纵坐标为 水体硝态氮的去除率(图 4). 无论在低负荷 $\left(\mathrm{NO}_{3}^{-}-\mathrm{N}\right.$ 约为 $\left.1.07 \mathrm{mg} / \mathrm{L}\right)$ 还是高负荷 $\left(\mathrm{NO}_{3}{ }^{-}-\mathrm{N}\right.$ 约为 $\left.3.37 \mathrm{mg} / \mathrm{L}\right)$ 条 件下, 水生植物湿地单元都表现出高于空白的硝态氮去除率, 且在高负荷条件下对硝态氮的去除效果更 好. 由第 10 天的硝态氮去除率看, 芦苇、花叶水苟和苦草湿地单元在高负荷条件下的去除率分别是低负 荷条件下的 2.8 倍、3.6 倍和 2.9 倍.
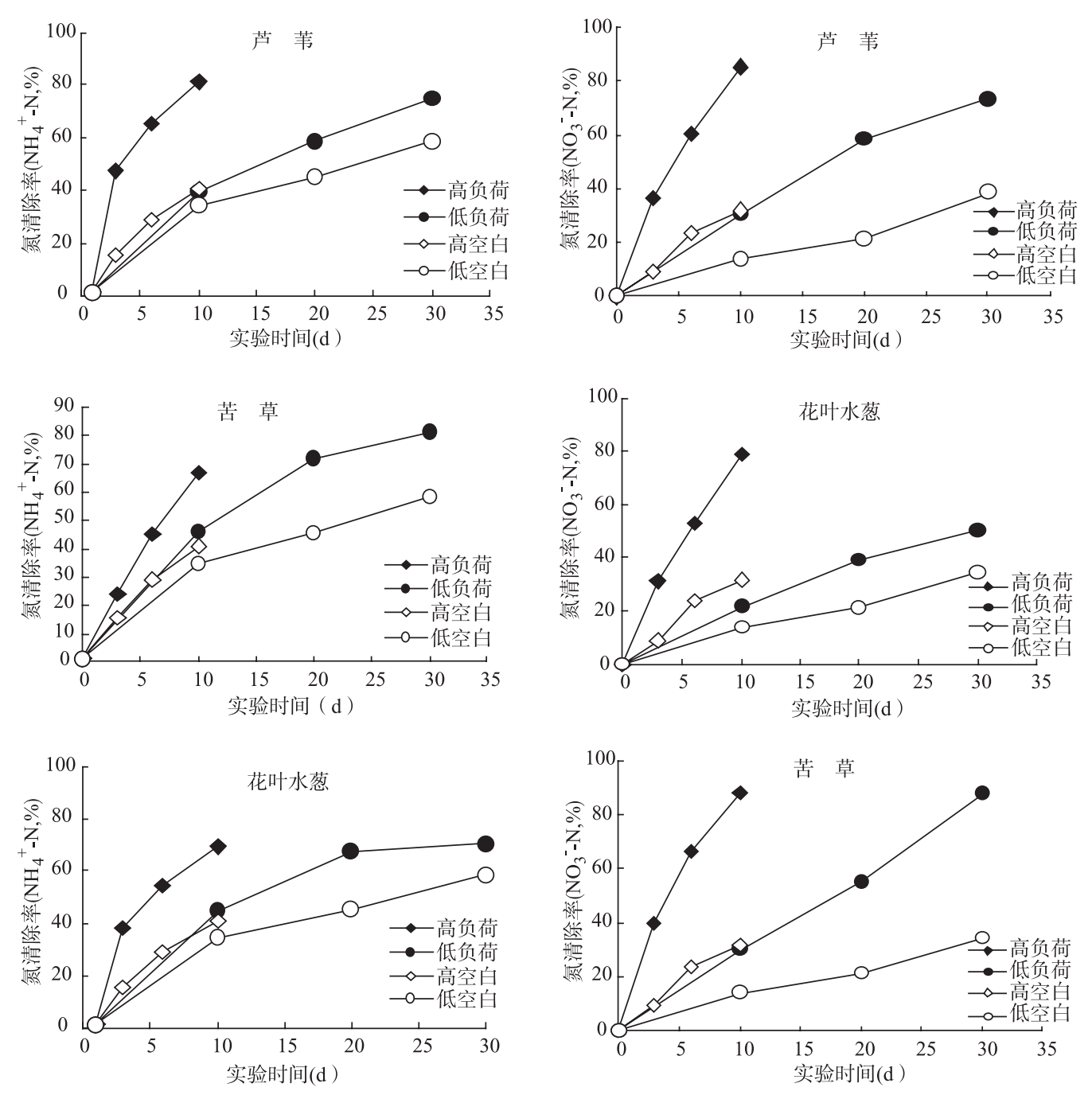

图 3 试验进程中不同水生植物湿地单元 对水体中铵态氮去除率的变化

图 4 试验进程中不同水生植物湿地单元对水体中 硝态氮去除率的变化

Fig.3 The removal rate of Ammonium in the wetland units with the different hydrophytes during the simulation

Fig.4 The removal rate of Nitrate in the wetland units with the different hydrophytes during the simulation 


\section{4 不同水生植物湿地单元对无机氮去除效果的对比}

根据对试验数据的整体分析看，水生植物对水体中的铵态氮和硝态氮都有明显的去除效果，尤其是 在水体氮负荷较大的情况下, 各水生植物类型湿地氮污染的去除率都较高. 而对于不同形态的无机氮素 来看, 与无水生植物的空白相比，水生植物对硝态氮的去除效果要好于铵态氮(图 5). 原因可能是一方面 铵态氮在湿地体系中的存在形态不稳定, 植物吸收的效果不明显, 另一方面由于 $\mathrm{NH}_{4}{ }^{+}-\mathrm{N}$ 和 $\mathrm{NO}_{3}{ }^{-}-\mathrm{N}$ 自身 所带电荷及存在的状态不同，植物对它们的吸收、同化和体内代谢等方面都表现出很大差异. 植物对 $\mathrm{NO}_{3}{ }^{-}-\mathrm{N}$ 的吸收和运输是大多数植物氮素营养代谢的第一步. 一般认为, 植物对 $\mathrm{NO}_{3}{ }^{-}-\mathrm{N}$ 的吸收是主动过程, 在细胞 膜上存在着 $\mathrm{NO}_{3}{ }^{-}-\mathrm{N}$ 的专性运输蛋白, 借助质膜 ATPase 水解产生的质子驱动力将 $\mathrm{NO}_{3}{ }^{-}-\mathrm{N}$ 运人膜内. 而 $\mathrm{NH}_{4}{ }^{+}-\mathrm{N}$ 的吸收则要通过 $\mathrm{NH}_{4}{ }^{+}$在质膜上先发生脱质子化作用, 形成的非质子化的 $\mathrm{NH}_{3}$ 后再进人细胞内 ${ }^{[17]}$.

水生植物对无机氮的去除过程，在试验初期净化速率较快，试验时间大约 $10 \mathrm{~d}$ 后达到净化速率相对 稳定的平台期, 总体呈对数增长趋势. 由于不同污染负荷条件下, 湿地单元对水体中氮污染的净化效果 有一定差别，且高氮负荷和氮低负荷的试验时间不同，因此，为进行归一化的对比，根据试验时间与去 除率的相关方程，按照 $10 \mathrm{~d}$ 试验时间计算各湿地单元的最大去除率，结果见表 1 和表 2 . 试验时间与体系 中氮的去除率变化的相关方程通过统计软件拟合而获得.
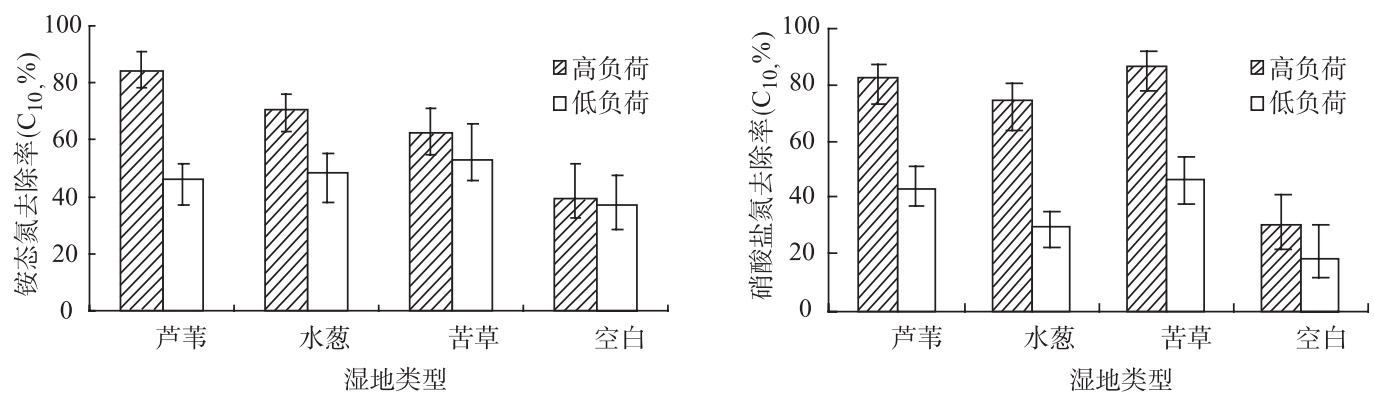

图 5 不同水生植物湿地单元对水体铵态氮(左图)和硝态氮(右图)去除率对比

Fig.5 The contrast of the wetland units with the different hydrophytes which removal rate of Ammonium and Nitrate

在高氮负荷条件下，芦苇、花叶水葱和苦草湿地单元对铵态氮的 $10 \mathrm{~d}$ 去除率分别为 $83.69 \% 、 70.56 \%$ 和 $62.52 \%$, 平均为 $72.26 \%$; 在低氮负荷条件下水生植物湿地单元对铵态氮的 $10 \mathrm{~d}$ 去除率分别为 $46.04 \%$ 、 $48.45 \%$ 和 $52.88 \%$, 平均 $49.12 \%$. 与空白对照湿地单元对比, 在低氮负荷条件下有植物湿地单元的铵态氮 去除率比无植物湿地单元铵态氮去除率高 $12.39 \%$, 而在高氮负荷条件下有植物湿地单元的铵态氮去除 率比无植物湿地单元铵态氮去除率高 33.04\%(表 1).

在高氮负荷条件下，芦苇、花叶水葱和苦草湿地单元对硝态氮的 $10 \mathrm{~d}$ 去除率分别为 $81.95 \% 、 74.26 \%$ 和 $86.71 \%$, 平均为 $80.97 \%$; 在低氮负荷条件下, 水生植物湿地单元对硝态氮的 $10 \mathrm{~d}$ 去除率分别为 $43.10 \%$ 、 $29.57 \%$ 和 $46.16 \%$, 平均为 $39.61 \%$. 在低氮负荷条件下有植物湿地单元的硝态氮去除率比无植物湿地单 元硝态氮的去除率高 $21.13 \%$, 而在高氮负荷条件下, 有植物湿地单元的硝态氮去除率比无植物的空白湿 地单元硝态氮的去除率高 $50.73 \%$ (表 2). 显然, 与铵态氮相比, 在高氮负荷条件下各类水生植物对硝态氮 去除作用的影响程度更高, 植物对硝酸盐氮的吸收可能有效降低了水体中的硝态氮浓度.

从水体中无机氮素的转化迁移时间看, 铵态氮较硝态氮更容易发生转化而从水体中迁移出来. 根据 表 1 和表 2 中所列出的试验时间与去除率相关关系方程分析计算结果显示，低氮负荷条件下有植物湿地 单元铵态氮的寄宿时间平均为 $15.24 \mathrm{~d}$, 硝态氮的寄宿时间平均为 $33.29 \mathrm{~d}$, 而无植物空白对照湿地中铵态 氮和硝态氮的寄宿时间分别为 $32.43 \mathrm{~d}$ 和 $509.43 \mathrm{~d}$; 在高氮负荷条件下，有植物湿地单元中铵态氮的寄宿时 间平均为 $7.35 \mathrm{~d}$, 硝态氮的寄宿时间平均为 $6.14 \mathrm{~d}$, 对照空白湿地中铵态氮和硝态氮的寄宿时间分别为 $26.58 \mathrm{~d}$ 和 58.96d. 可能的原因在于高浓度铵态氮条件下，植物的某种生理功能得到改善，一方面植物根系活力 
得以提高 ${ }^{[18]}$, 从而促进根际环境的变化, 有助于硝化、反硝化细菌等各种微生物的活动, 加速氮素的去除; 另一方面植物叶片的光合能力得到提高 ${ }^{[19-20]}$, 加速植物自身代谢过程, 促进其对体系中无机氮的吸收利 用. 而低氮负荷条件下, 湿地对氮素的去除可能以吸附、共沉、氨挥发、硝化作用等物理化学过程为主.

表 1 不同水生植物湿地单元中铵态氮去除试验的主要结果

Tab.1 The main results about the removal rate of Ammonium in the wetland units with the different hydrophytes

\begin{tabular}{|c|c|c|c|c|c|c|c|c|}
\hline \multirow[b]{2}{*}{$\begin{array}{l}\text { 湿地 } \\
\text { 类型 }\end{array}$} & \multicolumn{4}{|c|}{ 高负荷 $\left(\mathrm{NH}_{4}{ }^{+}-\mathrm{N}\right.$ 起始浓度约为 $\left.5.50 \mathrm{mg} / \mathrm{L}\right)$} & \multicolumn{4}{|c|}{ 低负荷 $\left(\mathrm{NH}_{4}{ }^{+}-\mathrm{N}\right.$ 起始浓度约为 $\left.2.85 \mathrm{mg} / \mathrm{L}\right)$} \\
\hline & 回归方程 & $\begin{array}{c}\text { 方差 } \\
\left(R^{2}\right)\end{array}$ & $\begin{array}{c}10 \mathrm{~d} \\
\text { 去除率 } \\
(\%)\end{array}$ & $\begin{array}{c}\text { 寄宿 } \\
\text { 时间 } \\
\text { (d) }\end{array}$ & 回归方程 & $\begin{array}{c}\text { 方差 } \\
\left(R^{2}\right)\end{array}$ & $\begin{array}{c}10 \mathrm{~d} \\
\text { 去除率 } \\
(\%)\end{array}$ & $\begin{array}{c}\text { 寄宿 } \\
\text { 时间 } \\
\text { (d) }\end{array}$ \\
\hline 芦苇 & $C=35.046 \ln T+2.9969$ & 0.9865 & 83.69 & 5.52 & $C=21.031 \ln T-2.3869$ & 0.9709 & 46.04 & 17.42 \\
\hline 花叶水葱 & $C=29.862 \ln T+1.7985$ & 0.9901 & 70.56 & 7.25 & $C=23.327 \ln T-0.6591$ & 0.9899 & 48.45 & 15.52 \\
\hline 苦草 & $C=28.464 \ln T-3.024$ & 0.9769 & 62.52 & 9.29 & $C=23.782 \ln T-1.8766$ & 0.9901 & 52.88 & 12.78 \\
\hline 空白 & $C=17.64 \ln T-1.3935$ & 0.9901 & 39.22 & 26.58 & $C=16.38 \ln T-0.9856$ & 0.9901 & 36.73 & 32.43 \\
\hline
\end{tabular}

表 2 不同水生植物湿地单元中硝态氮去除试验的主要结果

Tab.2 The main results about the removal rate of Nitrate in the wetland units with the different hydrophytes

\begin{tabular}{|c|c|c|c|c|c|c|c|c|}
\hline \multirow[b]{2}{*}{$\begin{array}{l}\text { 湿地 } \\
\text { 类型 }\end{array}$} & \multicolumn{4}{|c|}{ 高负荷 $\left(\mathrm{NO}_{3}{ }^{-}-\mathrm{N}\right.$ 起始浓度约为 $\left.3.37 \mathrm{mg} / \mathrm{L}\right)$} & \multicolumn{4}{|c|}{ 低负荷 $\left(\mathrm{NO}_{3}{ }^{-}-\mathrm{N}\right.$ 起始浓度约为 $\left.1.07 \mathrm{mg} / \mathrm{L}\right)$} \\
\hline & 回归方程 & $\begin{array}{c}\text { 方差 } \\
\left(R^{2}\right)\end{array}$ & $\begin{array}{c}10 \mathrm{~d} \\
\text { 去除率 } \\
(\%)\end{array}$ & $\begin{array}{c}\text { 寄宿 } \\
\text { 时间 } \\
\text { (d) }\end{array}$ & 回归方程 & $\begin{array}{c}\text { 方差 } \\
\left(R^{2}\right)\end{array}$ & $\begin{array}{c}10 \mathrm{~d} \\
\text { 去除率 } \\
(\%)\end{array}$ & $\begin{array}{c}\text { 寄宿 } \\
\text { 时间 } \\
\text { (d) }\end{array}$ \\
\hline 芦苇 & C & & 81.95 & 5.98 & $C=20.471$ & & 43.10 & 20.21 \\
\hline 花叶水葱 & $C=37.9911$ & 0.99 & 74.26 & 6.96 & $=2263 \ln T$ & & 29.57 & 62.57 \\
\hline 苦草 & $C=33.293 \ln T-2.3962$ & 0.9840 & 86.71 & 5.49 & $C=13.924 \ln T-2.4901$ & & 46.16 & 17.09 \\
\hline 空白 & $C=14.034 \ln T-2.0706$ & 0.9593 & 30.24 & 58.96 & $C=8.8426 \ln T-1.8775$ & 0.8844 & 18.48 & 509.43 \\
\hline
\end{tabular}

总体上看, 人工湿地对高氮负荷条件下无机氮的净化能力要优于低氮负荷条件. 由于以往的人工湿 地主要集中在对二级出水的处理, 而对原污水或初沉池出水的处理方面的资料尚且有限 ${ }^{[21]}$, 因此, 本试 验也为人工湿地的进一步应用提供了依据.

\section{3 结论}

通过以上试验研究, 可以初步得出以下几点结论:

1) 不同类型水生植物构成的湿地单元中环境条件演变表现出显著的差异性, 苦草等沉水植物使水 体更氧化，而芦苇、花叶水葱等挺水植物则可能使体系相对更为还原.

2) 在相同氮负荷条件下, 不同类型水生植物湿地体系中氮素的转化并没有表现出显著的差异, 与传 统认识中好氧条件有利于铵态氮的氧化过程, 还原条件降低体系的硝态氮负荷 ${ }^{[22]}$ 有所不同, 有待对其机 理进行深人研究.

3) 水生植物对湿地水体中的铵态氮和硝态氮都有明显的去除效果, 且在高氮负荷 $\left(\mathrm{NH}_{4}{ }^{+}-\mathrm{N}\right.$ 约为 $5.50 \mathrm{mg} / \mathrm{L}, \mathrm{NO}_{3}{ }^{-}-\mathrm{N}$ 约为 $3.37 \mathrm{mg} / \mathrm{L}$, 是一般城市河流污染程度的 2 倍)条件下的去除率高于在低氮负荷 $\left(\mathrm{NH}_{4}{ }^{+}-\mathrm{N}\right.$ 约为 $2.85 \mathrm{mg} / \mathrm{L}, \mathrm{NO}_{3}{ }^{-}-\mathrm{N}$ 约为 $1.07 \mathrm{mg} / \mathrm{L}$, 相当于一般城市污染河流 $)$ 条件下的去除率, 这就为人工 湿地对原污水或初沉池出水的处理提供了有力依据.

4) 对于不同形态的无机氮素, 与无水生植物的空白湿地单元相比, 有水生植物的湿地单元对硝态氮 的去除效果高于铵态氮.

5) 水生植物可有效促进湿地体系中氮素的转化过程，显著缩短无机氮素在湿地体系中的寄宿时间. 


\section{4 参考文献}

[1]＼cjkstart杜桂森，吴玉梅，杨忠山等. 北京城区河湖水质分析. 湖泊科学, 2005, 17(4): 373-377.

[2] 徐治国, 何 岩, 间百兴. 沼泽湿地对污水中 $\mathrm{NH}_{4}{ }^{+}-\mathrm{N}$ 和 $\mathrm{PO}_{4}{ }^{3-}-\mathrm{P}$ 净化模拟研究. 湿地科学, 2005, 3(2): 110-115.

[3] Verhoeven JTA, Meuleman AFM. Wetlands for wastewater treatment: Opportunities and limitations. Ecological Engineering, 1999, 12: 5-12.

[4] 白军红, 欧阳华, 邓 伟等. 湿地氮素传输过程研究进展. 生态学报, 2005, 25(2): 326-333.

[5] Rogers KH, Breen PF, Chick AJ. Nitrogen removal in experimental wetland treatment system: evidence for the role of aquatic plants. Res Journal of WPCF, 1991, 63(7): 934-941.

[6] 刘景双. 湿地生物地球化学研究. 湿地科学, 2005, 3(4): 302-308.

[7] 雷泽湘, 谢贻发, 徐德兰等. 大型水生植物对富营养化湖水净化效果的实验研究. 安徽农业科学, 2006, 34(3): 553-554.

[8] 刘来胜, 周怀东, 董哲仁等. 模拟湿地中磷的去除规律初步研究. 湖泊科学, 2005, 17(4): 361-365.

[9] 李睿华, 管运涛, 何苗等. 河岸芦苇、荠白和香蒲植物带处理受污然河水中试研究. 环境科学, 2006, 27(3): 493-497.

[10] 国家环境保护总局《水和废水监测分析方法》编委会. 水和废水监测分析方法(第四版). 北京: 中国环境科学出版社, 2002.

[11] 付融冰, 杨海真, 顾国维等. 潜流人工湿地对农村生活污水氮去除的研究. 水处理技术, 2006, 32(1): 18-22.

[12] 李科德, 胡正嘉. 人工模拟芦苇系统处理污水的效能. 华中农业大学学报, 1994, 13(5): 511-517.

[13] Nichols DS, Keeney DR. Nitrogen nutrition of Myriophyllum spicatum: uptake and translocation of $15 \mathrm{~N}$ by shoots and roots. Freshwater Biol, 1976, 6: 145-154.

[14] 黄 蕾, 翟建平, 蒋金金炎等. 三种水生植物在不同季节去污能力的对比研究. 环境保护科学, 2005, 31(129): 44-47.

[15] 高建华, 欧维山, 杨桂山. 潮滩湿地 N、P 生物地球化学过程研究. 湿地科学, 2004, 2(3): 220-227.

[16] Jiang SR, Lin YF, Lee DY et al. Nutrient removal from polluted river water by using constructed wetlands. Bioresource Technology, 2001,76: 131-135.

[17] 李春俭. 土壤与植物营养研究新动态(第四卷). 北京: 中国农业出版社, 2001: 122-132.

[18] Majerowicz N, Kerbauy GB, Nievola CC et al. Growth and nitrogen metabolism of Catasetum fimbriatum (orchidaceae) grown with different nitrogen sources. Enviromental and Experimental Botany, 2000, 44: 195-206.

[19] Blanke MM, Bacher W, Pring RJ et al. Ammonium nutrition enhances chlorophyll and glaucousness in Kohlrabi. Annals of Botany, 1996,78: 599-604.

[20] Claussen W, Lenz F. Effect of ammonium or nitrate nutrition on net photosynthesis, growth, and activity of the enzymes nitrate reductase and glutamine synthetase in blueberry, raspberry and strawberry. Plant and Soil, 1999, 208: 95-102.

[21] 王世和. 人工湿地污水处理理论与技术. 北京: 科学出版社, 2007: 12 .

[22] Kadlee RH, Knight RL. Treatment wetlands. Boca Raton, FL: Lewis Publishers, 1996. 